\title{
Hippocampal Place Cell Firing Patterns Can Induce Long-Term Synaptic Plasticity In Vitro
}

\author{
John T. R. Isaac, ${ }^{1,2}$ Katherine A. Buchanan, ${ }^{1,3}$ Robert U. Muller, ${ }^{1,4}$ and Jack R. Mellor ${ }^{1}$ \\ ${ }^{1}$ Medical Research Council Centre for Synaptic Plasticity, Department of Anatomy, University of Bristol, Bristol BS8 1TD, United Kingdom, ${ }^{2}$ National \\ Institute for Neurological Disorders and Stroke-National Institutes of Health, Bethesda, Maryland 20892, ${ }^{3}$ Department of Neuroscience, Physiology and \\ Pharmacology, University College London, London WC1E 6BT, United Kingdom, and ${ }^{4}$ Health Science Center at Brooklyn, State University of New York, \\ Brooklyn, New York 11203
}

In the hippocampus, synaptic strength between pyramidal cells is modifiable by NMDA receptor (NMDAR)-dependent long-term potentiation (LTP) and long-term depression (LTD), both of which require coincident presynaptic and postsynaptic activity. In vivo, many pyramidal cells exhibit location-specific activity patterns and are known as "place cells." The combination of these factors suggests that synaptic plasticity will be induced at synapses connecting place cells with overlapping firing fields, because such cells fire coincidentally when the rat is in a specific part of the environment. However, this prediction, which is important for models of how long-term synaptic plasticity can be used to encode space in the hippocampal network, has not been tested. To investigate this, action potential time series recorded simultaneously from place cells in freely moving rats were replayed concurrently into postsynaptic CA1 pyramidal cells and presynaptic inputs during perforated patch-clamp recordings from adult hippocampal slices. Place cell firing patterns induced large, pathway-specific, NMDAR-dependent LTP that was rapidly expressed within a few minutes. However, place-cell LTP was induced only if the two place cells had overlapping firing fields and if the cholinergic tone present in the hippocampus during exploration was restored by bath application of the cholinergic agonist carbachol. LTD was never observed in response to place cell firing patterns. Our findings demonstrate that spike patterns from hippocampal place cells can robustly induce NMDAR-dependent LTP, providing important evidence in support of a model in which spatial distance is encoded as the strength of synaptic connections between place cells.

\section{Introduction}

Synapses between hippocampal pyramidal cells undergo long lasting, use-dependent changes in strength [long-term potentiation (LTP) and long-term depression (LTD)] that requires NMDA receptor (NMDAR) activation by appropriately timed presynaptic and postsynaptic activity (Bliss and Collingridge, 1993; Malenka and Bear, 2004). These use-dependent plastic processes are under intense investigation because they are accepted as the best candidates for neural substrates of hippocampal-based memory (Martin et al., 2000; Nakazawa et al., 2004). Generally, investigations of NMDAR-dependent plasticity including LTP and LTD have used artificial stimulus protocols (Dunwiddie and Lynch, 1978; Kauer et al., 1988; Dudek and Bear, 1992), including some modeled on "physiological" activity patterns (Larson et al., 1986; Magee and Johnston, 1997; Dobrunz and Stevens, 1999). However, it has never been established whether long-term syn-

Received Feb. 12, 2009; revised March 25, 2009; accepted April 13, 2009.

We are grateful to the Wellcome Trust (J.R.M., J.T.R.I.), the Medical Research Council (J.R.M., R.U.M.), the European Union Network of European Neuroscience Institutes (J.R.M.), GlaxoSmithKline (K.A.B.), and National Institutes of Health extramural (Grant NS20686 to R.U.M.) and National Institute of Neurological Disorders and Stroke intramural (J.T.R.I.) programs for financial support. We thank Y. Li for converting in vivo recorded data into timestamp format for replay.

Correspondence should be addressed to Jack R. Mellor, Medical Research Council Centre for Synaptic Plasticity, Department of Anatomy, University of Bristol, Bristol BS8 1TD, UK. E-mail: jack.mellor@bristol.ac.uk. DOI:10.1523/JNEUROSCI.0731-09.2009

Copyright $\odot 2009$ Society for Neuroscience $\quad$ 0270-6474/09/296840-11\$15.00/0 aptic plasticity can be induced by hippocampal firing patterns found in vivo.

To address this, we focused on place cell activity, a prominent, natural form of hippocampal pyramidal cell firing. Place cells are a subset of hippocampal pyramidal cells characterized by location-specific discharge; each place cell is intensely active only when the rat's head is in a stable, cell-specific region called the "firing field" and is otherwise nearly silent (O'Keefe and Dostrovsky, 1971; Muller et al., 1987; Buzsáki, 2005). Because the fields of hundreds of thousands of place cells are evenly distributed over the surface of an environment (Muller et al., 1987) and there is a high degree of connectivity among hippocampal CA3CA3 and CA3-CA1 pyramidal cells (Li et al., 1994), any pair of regions in a local environment will be represented by hundreds of connected place cell pairs. Because the timing of activity in the presynaptic and postsynaptic elements of a synapse between two place cells varies with the distance between their firing fields, synapses formed between place cells with coincident fields may undergo LTP, whereas synapses formed by place cells with widely separated fields will undergo no change in strength. Thus, longterm synaptic plasticity between place cells could be used to encode spatial distance (Muller et al., 1996).

Here we investigate this by studying whether long-term synaptic plasticity in CA1 hippocampus can be induced in slices by location-specific place cell activity obtained from in vivo recordings. We used the discharge of pairs of simultaneously recorded hippocampal place cells to control presynaptic input and 
A Hippocampal place cell recordings
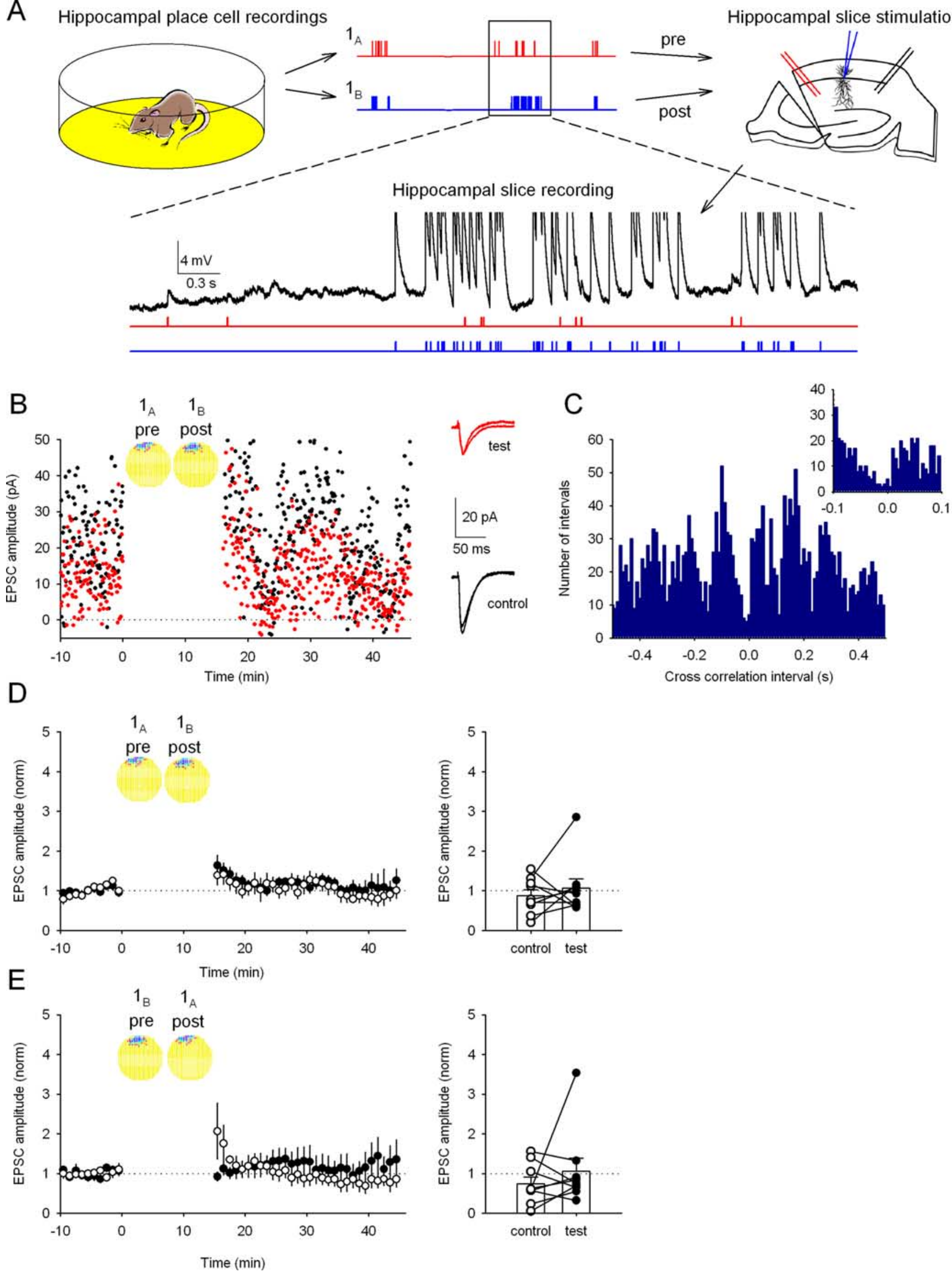
postsynaptic firing of CA1 pyramidal cells in hippocampal slices, similar to an approach used to study plasticity in visual cortex (Froemke and Dan, 2002). We find that such dual stimulation from pairs of place cells with overlapping firing fields induces robust NMDAR-dependent LTP, but this depends on mimicking, with bath-applied carbachol, the increased cholinergic tone found in the hippocampus during locomotion. However, widely separated firing fields induced no synaptic strength change, and studies of partially overlapping fields demonstrate a steep dependency on firing field overlap for LTP induction. Our experiments provide direct evidence that place cell firing induces hippocampal NMDAR-dependent LTP and provide important support for a model (Muller et al., 1996) of how such LTP could be used to encode spatial information in the hippocampus.

\section{Materials and Methods}

Place cell recording. Place cell recordings were performed as described previously (Muller et al., 1987). Briefly, hungry male adult rats were placed in a familiar 76-cm-diameter cylindrical environment. Food pellets were dropped randomly to encourage constant movement and even coverage of the floor. By tracking a light-emitting diode on the electrode implant, the rat's head position was found at $60 \mathrm{~Hz}$ in a grid of square pixels $2.7 \mathrm{~cm}$ on a side. Action potential activity from groups of place cells was recorded from microwires or tetrodes in the CA1 or the CA3 areas of the hippocampus; CA1 cells were predominantly used, but CA1 and CA3 place cell firing patterns are essentially indistinguishable (Muller et al., 1987; Lee et al., 2004). Action potentials from place cells were converted to time stamps that were used in the in vitro experiments (see Fig. 1). Place cell activity was also combined with positional measurements to reveal spatial firing rate distributions (see colored firing rate maps shown as figure insets). Place cell pairs with overlapping firing fields were recorded from different electrodes. Data for the 16 min recordings from the 12 cells used for stimulation are shown in supplemental Figure 1 (avail-

Figure 1. Synaptic plasticity is not induced by replay of activity from place cells with overlapping firing fields under standard hippocampal slice recording conditions. A, Experimental procedure. Top, Spike activity from two hippocampal place cells with overlapping firing fields $\left(1_{A}\right.$ and $\left.1_{B}\right)$ is recorded from a rat during food foraging in a 0.75 -m-diameter cylindrical environment. Each cell fires a burst whenever the rat's head enters the firing field of the cell; the cells tend to fire together because their firing fields nearly superimpose in the environment (see $\boldsymbol{B}, 1_{A}$ and $1_{B}$ ). Waveforms are converted to timestamp format and used to stimulate neural elements in a hippocampal slice. The timestamp from cell $A$ is used to trigger action potentials in presynaptic axons (red); cell B is used to trigger action potentials in a postsynaptic CA1 pyramidal cell via a perforated-patch electrode (blue). Bottom, Activity evoked in the CA1 neuron is shown on an expanded timescale (black trace) together with the timestamps (red and blue). EPSPs are visible when only a stimulus from cell $A$ is applied. Spikes (truncated in this illustration) are seen in response to stimuli from cell B. B, Example showing EPSC amplitudes for the test (red) and control (black) input pathways before and after a 16 min gap, during which the activity from the place cell pair was replayed. The circular insets show the overlapping firing fields of cell $1_{A}$, used to control the test axonal input, and cell $1_{B}$, used to control the postsynaptic cell. In these false color maps, yellow encodes pixels in which the firing rate was exactly zero; higher rates are shown in darker colors. Right, Averaged EPSC traces recorded before and after replay of cell pair $1_{A, B}$ activity in test and control pathways. The lack of plasticity is indicated by the near identity of responses. $C$, Cross-correlation histogram (10 ms bins) for cells $1_{A}$ and $1_{B}$; negative intervals show that cell $1_{A}$ fired before cell $1_{B}$, and positive intervals show that cell $1_{B}$ fired before cell $1_{A}$. Successive peaks indicate modulation by the $8 \mathrm{~Hz}$ theta rhythm characteristic of walking. Note the count minimum near $t=0$. Inset, The same data on an expanded timescale (5 ms bins) emphasizing the asymmetric distribution of counts at approximately $t=0$. D , No synaptic plasticity is induced on average by replay of activity from cell pair $1_{A, B}$. Each time point is the normalized EPSC amplitude averaged from nine experiments as in $\boldsymbol{B}$ (control pathway, $74 \pm$ $17 \%$ of baseline; test pathway, $106 \pm 32 \% ; p>0.05$ control vs test). Right, (hange in EPSC amplitude for the control and test pathways in each experiment. $\boldsymbol{E}$, Reversing stimulation in the slice so that cell $1_{\mathrm{A}}$ now controls postsynaptic stimulation and cell $1_{\mathrm{B}}$ controls presynaptic stimulation (replay of pair $1_{B, A}$ ) induces no synaptic plasticity (control path, $87 \pm 15 \%$; test path, $106 \pm 24 \% ; n=9$ cells; $p>0.05$ ). Right, Change in EPSC amplitude for the control and test pathways in each experiment. able at www.jneurosci.org as supplemental material). Cells $1_{\mathrm{A}}, 1_{\mathrm{B}}$, and $1_{\mathrm{C}}$ were published previously (Muller et al., 1996). Cells $2_{\mathrm{A}}, 2_{\mathrm{B}}, 2_{\mathrm{C}}, 2_{\mathrm{D}}, 2_{\mathrm{E}}$, $3_{\mathrm{A}}, 3_{\mathrm{B}}, 4_{\mathrm{A}}$, and $4_{\mathrm{B}}$ were not published previously. For cells $1_{\mathrm{A}}, 1_{\mathrm{B}}$, and $1_{\mathrm{C}}$ occasional activity outside of firing fields from other cells attributable to poorly discriminated waveforms was removed. In the color-coded firing map insets in the figures, firing rate is color coded (yellow, $0 \mathrm{~Hz}$ up to purple, maximum rate) (for values for each cell used, see table in supplemental Fig. 1, available at www.jneurosci.org as supplemental material), and white pixels were never visited. To estimate the degree of overlap between firing field pairs, we calculated an overlap index of the number of pixels in common for the two firing fields divided by the total number of pixels in the larger field. In this way, the larger the index value, the greater the degree of overlap, but the overlap index cannot be as large as 1.0 unless the two fields are congruent.

Hippocampal slice recording. Hippocampal slices (400 $\mu \mathrm{m}$ thick) were prepared from adult $(200 \mathrm{~g})$ male Wistar rats. Slices were cut in ice-cold artificial CSF (aCSF) containing the following (in $\mathrm{mm}$ ): $126 \mathrm{NaCl}, 10$ glucose, $26 \mathrm{NaHCO}_{3}, 2.5 \mathrm{KCl}, 1.2 \mathrm{NaHPO}_{4}, 1 \mathrm{CaCl}_{2}$, and $5 \mathrm{MgSO}_{4}$ (saturated with $95 \% \mathrm{O}_{2}, 5 \% \mathrm{CO}_{2}$ ). Slices were then transferred to recording aCSF $\left(\mathrm{CaCl}_{2}\right.$ and $\mathrm{MgSO}_{4}$ adjusted to 2.5 and $1.3 \mathrm{~mm}$, respectively) and heated to $35^{\circ} \mathrm{C}$ for $30 \mathrm{~min}$. Slices were thereafter stored at room temperature. For recording, a cut was made between CA 3 and CA1, and slices were immersed in a submerged recording chamber in the presence of picrotoxin $(100 \mu \mathrm{M})$ at $35^{\circ} \mathrm{C}$. Perforated-patch voltage-clamp recordings were made from visually identified CA1 pyramidal neurons using borosilicate glass pipettes of $2-6 \mathrm{M} \Omega$ resistance, tip filled with a solution containing the following (in mM): $117 \mathrm{KMeSO}_{3}, 8 \mathrm{NaCl}, 10 \mathrm{HEPES}, 5$ QX-314 [N-(2,6-dimethylphenylcarbamoylmethyl)triethylammonium chloride], 4 MgATP, 0.3 NaGTP, and 0.2 EGTA, pH 7.4 (280 mOsm). Pipettes were backfilled with a solution identical to that above but to which gramicidin $(80 \mu \mathrm{g} / \mathrm{ml})$ or in a few cases amphotericin B $(0.6 \mathrm{mg} /$ $\mathrm{ml}$ ) was added. Gramicidin and amphotericin B were prepared as stock solutions in DMSO (20 and $100 \mathrm{mg} / \mathrm{ml}$, respectively). After formation of a gigaohm seal, the access resistance was monitored and recordings were commenced once stable. Access resistances averaged $45.7 \pm 1.8 \mathrm{M} \Omega(n=$ 118 ), and recordings were not used if the access resistance changed by $>20 \%$ during data collection. Spontaneous rupture of the patched membrane was checked by monitoring access resistance and the ability to fire action potentials (the sodium channel blocker QX-314 was present in the patch solution).

Bipolar stimulating electrodes were placed proximally in stratum radiatum $>200 \mu \mathrm{m}$ on either side of the recorded CA1 pyramidal neuron, and stimulation intensity was set just above threshold for evoking detectable EPSCs. Stimulus frequency was $0.2 \mathrm{~Hz}$ for each pathway. It was necessary to use CA3-CA1 synapses rather than the functionally very similar CA3-CA3 synapses to avoid complicated activity patterns from reverberatory excitation attributable to recurrent CA3 connections. Spikes from in vivo place cell recordings were converted to time series of pulses (sampling rate, $10 \mathrm{KHz}$ ), which were used to drive a stimulation box to activate presynaptic axons or to drive current steps in the postsynaptic CA1 pyramidal neuron to produce action potentials at the precise times dictated by the time series. For replay of place cell activity during the 16 min induction period, the recording was switched to currentclamp mode and the CA1 neuron was stimulated to fire action potentials by $2 \mathrm{~ms}$ current injections of 1-1.5 nA. For each recording, we ensured that these current steps produced postsynaptic action potentials that were precisely synchronized to the time series input. Recordings of carbachol effects on membrane potential and EPSC amplitude (see Fig. $2 A, B$ ) were performed in separate experiments using the whole-cell configuration with the same pipette filling solution as above (but lacking the perforating antibiotic and QX-314 $\mathrm{Cl}$ ). For perforated-patch experiments in which cesium was substituted for potassium (see Fig. 6), the pipette solution contained the following (in $\mathrm{mM}$ ): $117 \mathrm{CsMeSO}_{4}, 8 \mathrm{NaCl}$ 10 HEPES, 5 QX-314 Cl, 4 MgATP, 0.3 NaGTP, 0.2 EGTA, and gramicidin, pH 7.4 (280 mOsm).

All data were sampled at $10 \mathrm{kHz}$, filtered at $5 \mathrm{kHz}$, and recorded onto computer using Signal or Spike acquisition software (Cambridge Electronic Design). Analyses were performed with scripts written in this software environment. Failure analysis was performed by calculating the 
noise distribution at $\sim 0 \mathrm{pA}$ and subtracting this from the EPSC amplitude histogram. The failure rate for all cells was on average $19.7 \pm 1.1 \%$ $(n=240)$, with a range of 0 to $95 \%$ (supplemental Fig. 2, available at www.jneurosci.org as supplemental material). For perforated-patch recordings with $\mathrm{K}^{+}$-based solution, the average EPSC size including failures was $9.6 \pm 0.4 \mathrm{pA}(n=208)$, with a range of 1.3 to $38.2 \mathrm{pA}$, and the corresponding potency (EPSC amplitude excluding failures) was $11.7 \pm$ $0.4 \mathrm{pA}(n=208)$. Failure rates and EPSC amplitudes were similar for test and control pathways. EPSP amplitudes measured during replay of place cell activity were made for all EPSPs, except those that occurred $<50 \mathrm{~ms}$ after a postsynaptic action potential, and binned every $30 \mathrm{~s}$. Values for changes in synaptic strength are taken as the average from 21 to $30 \mathrm{~min}$ after the end of the induction period. Renormalization of test compared with control pathways was performed for each individual experiment and then averaged across experiments. Data are presented as mean \pm SEM, and statistical tests were performed as paired Student's $t$ test unless otherwise stated. D-APV, picrotoxin, and carbachol were purchased from Tocris Cookson.

\section{Results}

\section{Replaying firing patterns from pairs of place cells into presynaptic and postsynaptic elements in the hippocampal slice}

The anatomy of connections between pyramidal cells in the intact hippocampus predicts that there are $\sim 100,000$ synapses between place cells with similar firing fields in any given environment. Thus, it is very likely that many place cells with overlapping firing fields are synaptically connected. To study the effect of coincident place cell firing patterns on synaptic strength between place cell pairs, we evoked action potentials in postsynaptic CA1 pyramidal cells and in presynaptic afferent axons using firing patterns from place cell pairs simultaneously recorded in vivo (Fig. 1A). The place cell firing patterns came from $16 \mathrm{~min}$ in vivo recording sessions whose entire duration was used to generate equivalent patterns of activity in the slice (for the activity patterns of all the place cells used in the study, see supplemental Fig. 1, available at www.jneurosci.org as supplemental material). One place cell firing pattern was converted to a pulse time series that drove a stimulator for activating presynaptic axons via an extracellular stimulating electrode. Activity from the second place cell of the simultaneously recorded pair was converted to current steps that were used to evoke action potentials in the postsynaptic CA1 pyramidal neuron during perforated-patch recordings. Perforated-patch recordings were used to avoid washout of LTP signaling pathways that occurs during whole-cell patch-clamp recordings and can prevent reliable induction of LTP (Malinow and Tsien, 1990). Recordings were performed in slices from adult rats at close to physiological temperature. For presynaptic activation, minimal stimulation of afferent axons (Isaac et al., 1996) was used to activate one or a few synapses (failure rate, $19.7 \pm 1.1 \%$ for 240 synaptic connections) to mimic a unitary CA3-CA1 connection (Sorra and Harris, 1993) (supplemental Fig. 2, available at www.jneurosci.org as supplemental material). After collection of a stable baseline of EPSCs evoked at $0.2 \mathrm{~Hz}$ in voltage clamp, the paired place cell firing patterns were applied while recording in current-clamp mode. After this 16 min induction period, the cell was returned to voltage clamp, and the synaptic response was once again measured at $0.2 \mathrm{~Hz}$ to assay for changes in synaptic strength. A second, independent input onto the same cell was left quiescent during the induction protocol (i.e., was never subjected to replay of place cell activity), thereby serving as a control to allow assessment of input specificity of any induced plasticity.

\section{Overlapping firing fields do not induce LTP under standard slice recording conditions}

In a first set of experiments, place cell pair $1_{\mathrm{A}, \mathrm{B}}$ with overlapping fields was used; activity from cell A was used to drive action potentials in the presynaptic axon, and activity from cell B was used to drive action potentials in the postsynaptic cell. Despite considerable near-coincident activity (Fig. $1 A$, inset; firing rate maps in $B$; cross-correlations in $C$ ), no long-lasting change in synaptic strength was induced during the example experiment (Fig. $1 B$ ) or for the average of nine experiments (Fig. 1D). Similarly, reversing the roles of the two place cells during the induction period, so that cell A drove the postsynaptic cell and cell B activated the presynaptic input $\left(1_{\mathrm{B}, \mathrm{A}}\right)$, did not yield any longlasting synaptic strength change (Fig. $1 E$ ), despite the asymmetric cross-correlation function for this pair (minimum, approximately $\Delta t=0$; local maxima, $\Delta t= \pm 50-100 \mathrm{~ms}$ ) (Fig. 1C).

\section{Place cell firing patterns robustly induce LTP in the presence of carbachol}

Exploration of the environment and ongoing locomotion cause increased acetylcholine release in the hippocampus. In turn, this increased cholinergic tone facilitates spatial learning (Dudar et al., 1979; Leung et al., 2003; Hasselmo, 2006). Acetylcholine has several effects on CA1 pyramidal neurons, including suppression of a $\mathrm{K}^{+}$conductance (Ben-Ari et al., 1981), enhancement of NMDAR-mediated EPSPs (Markram and Segal, 1990), and the promotion of theta frequency oscillations in neuronal membrane potential (Chapman and Lacaille, 1999; Buzsáki, 2002). Although the place cell firing patterns we use exhibit modulation by the underlying theta rhythm (see the $\sim 8 \mathrm{~Hz}$ oscillations in the crosscorrelograms of Figs. $1 C, 3 A, C, E, 5 E$ ) (supplemental Fig. 1, available at www.jneurosci.org as supplemental material), cholinergic tone is absent in the hippocampal slice. We therefore asked whether plasticity is inducible after cholinergic tone is restored by bath application of the nonhydrolysable cholinergic agonist carbachol $(5 \mu \mathrm{M})$. By itself, this relatively low dose of carbachol caused a slow, reversible decrease in EPSC amplitude (26.7 \pm $6.5 \% ; n=5$ cells) (Fig. $2 A$ ) and a slow, reversible depolarization of membrane potential $(2.9 \pm 1.2 \mathrm{mV} ; n=9$ cells) (Fig. $2 B$ ); however, carbachol had no effect on the shape or precision of action potentials evoked in the postsynaptic cell during replay of place cell activity. When carbachol was present during the $16 \mathrm{~min}$ induction protocol, activity from cell pair $1_{\mathrm{A}, \mathrm{B}}$ produced robust, pathway-specific LTP (256 $\pm 60 \% ; n=12$ cells) (Fig. 2C,D). Despite the asymmetry of the cross-correlogram as noted above, induction with the reversed pair $1_{\mathrm{B}, \mathrm{A}}$ also produced robust, pathway-specific LTP $(346 \pm 62 \% ; n=8$ cells) (Fig. $2 E)$. Importantly, addition of D-APV $(50 \mu \mathrm{M})$ in the bath during replay of place cell firing (Fig. $2 F$ ) blocked LTP, showing that it is NMDAR dependent. Thus, carbachol is permissive for overlapping place cell firing patterns to cause input-specific, NMDAR-dependent LTP.

To test whether the ability to induce LTP with overlapping fields is a general feature of place cell spike trains, we used three other place cell pairs recorded from two other rats (cells $4_{\mathrm{A}, \mathrm{B}}, 2_{\mathrm{A}, \mathrm{B}}$, and $\left.2_{\mathrm{C}, \mathrm{D}}\right)$. First we used a pair of place cells, one of which was a CA3 pyramidal cell (cell $4_{\mathrm{A}}$ ) and the other a CA1 pyramidal cell (cell $4_{\mathrm{B}}$ ), to test whether CA3 place cell activity can induce LTP similar to CA1 place cell firing. Replay of cell $4_{\mathrm{A}}$ activity into the presynaptic axon and cell $4_{\mathrm{B}}$ into the postsynaptic cell in the presence of carbachol also caused large, robust, pathway-specific LTP $(436 \pm 140 \% ; n=6)$ (Fig. $3 A, B)$. We next tested two additional pairs of CA1 place cells whose firing fields were in virtually 
A
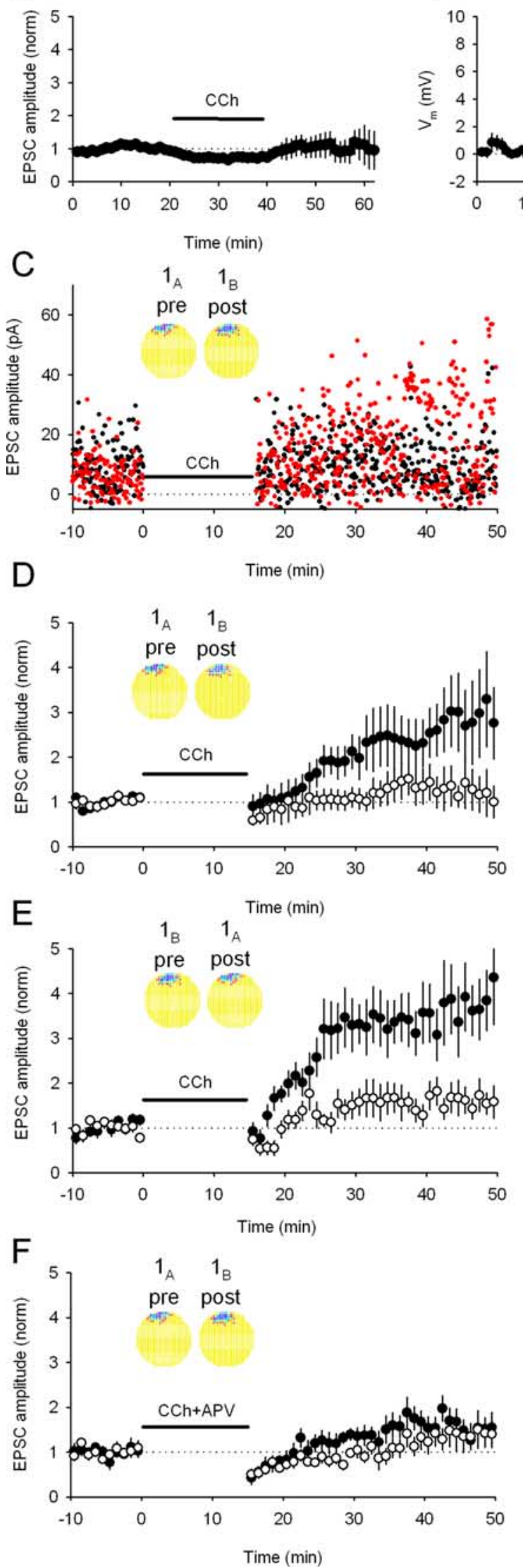

B

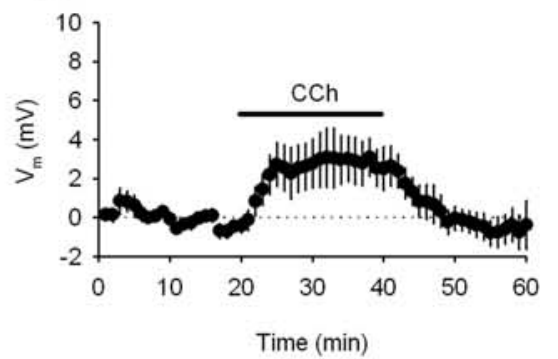

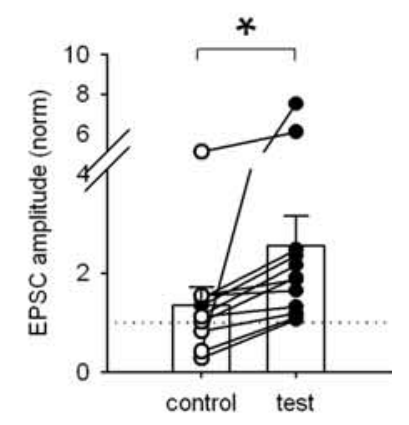
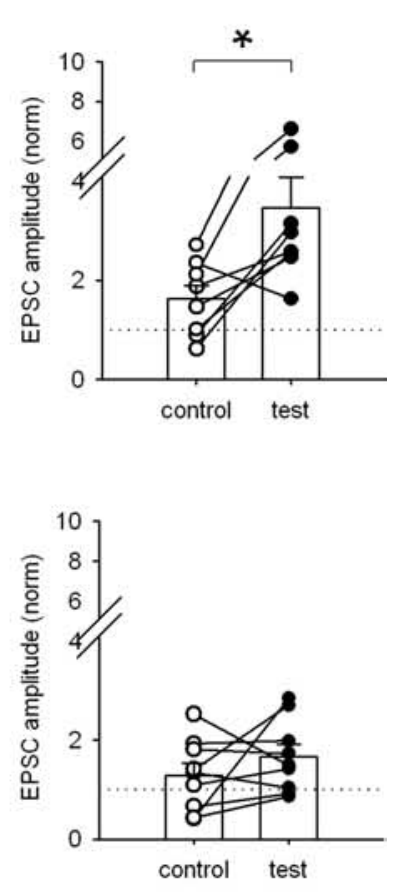

Figure 2. Bath application of carbachol enables LTP induction by activity from overlapping place cells. $\boldsymbol{A}$, In control experiments, carbachol (CCh; $5 \mu \mathrm{m})$ produces a reversible $26.7 \pm 6.5 \%(n=5$ cells) depression in the amplitude of unpotentiated EPSCs. $B$, Carbachol $(5 \mu \mathrm{m})$ produces a reversible $2.9 \pm 1.2 \mathrm{mV}(n=9$ cells) depolarization in the membrane potential of CA1 pyramidal neurons. $C$, Replay of

the same place, although they differed from one another and from the previously tested pairs in the number and temporal pattern of near-coincident spikes (see cross-correlograms in Figs. 1C, 3C,E) (supplemental Fig. 1, available at www. jneurosci.org as supplemental material); in particular, the cross-correlograms for the pairs $4_{\mathrm{A}, \mathrm{B}}, 2_{\mathrm{A}, \mathrm{B}}$, and $2_{\mathrm{C}, \mathrm{D}}$ are maximal very near $t=0$ in contrast to a minimum near $t=0$ for pair $1_{\mathrm{A}, \mathrm{B}}$. Despite these differences, each additional pair produced large, input-specific LTP in the presence of carbachol (cell $2_{\mathrm{A}, \mathrm{B}}, 317 \pm 117 \%, n=8$ cells; cell $2_{\mathrm{C}, \mathrm{D}}, 449 \pm 105 \%, n=8$ cells) (Fig. $3 D, F$ ). This suggests that the ability to induce LTP is common to place cells with near-coincident firing fields. Interestingly, the degree of potentiation produced by the four overlapping pairs was similar, despite considerable differences in their cross-correlations in intervals of $\pm 50 \mathrm{~ms}$ known to be important for induction of synaptic plasticity (Markram et al., 1997; Bi and Poo, 1998; Sjöstrom et al., 2001; Wittenberg and Wang, 2006).

Spike-timing-dependent plasticity (STDP) predicts that spikes occurring in the presynaptic cell less than $\sim 50 \mathrm{~ms}$ before a spike in the postsynaptic cell are critical for the induction of LTP. We tested this for place-cell-induced LTP using pair $1_{\mathrm{A}, \mathrm{B}}$ and removing all spikes from the postsynaptic cell $\left(1_{\mathrm{B}}\right)$ that occurred $<100$ ms after a spike in the presynaptic cell $\left(1_{\mathrm{A}}\right)$ (Fig. 4A). When this altered pair of cells was applied, no LTP was induced ( $88 \pm$ 20\%) (Fig. 4B). This demonstrates the requirement for near-coincident activity for the induction of LTP, consistent with conclusions from previous studies of STDP

$\leftarrow$

activity from place cell pair $1_{A, B}$ in the presence of $5 \mu \mathrm{m}$ carbachol now induces LTP in the test pathway (red) but not in the control pathway (black) in this example experiment. Insets, Firing rate maps for place cells $1_{A}$ and $1_{B}$. Right, Averaged EPSC traces recorded before and after replay of place cell activity. The test pathway shows considerable potentiation; the control pathway is unchanged. $\boldsymbol{D}$, Averaged data (using cell pair $1_{A, B}$ ) shows that pathway-specific LTP is reliably induced (control path, $135 \pm 37 \%$; test path, $256 \pm 60 \% ; n=12$ cells; $p<0.05)$. Right, Change in EPSC amplitude for each pathway in each experiment. ${ }^{*} p<0.05$. $E$, Reversing stimulation in the slice so that cell $1_{A}$ now controls postsynaptic stimulation and cell $1_{B}$ controls presynaptic stimulation (replay of pair $1_{B, A}$ ) induces pathway-specific LTP (control path, $163 \pm 27 \%$; test path, $346 \pm 62 \% ; n=8$ cells; $p<0.05$ ). Right, Change in EPSC amplitude for each pathway in each experiment. ${ }^{*} p<$ 0.05. $\boldsymbol{F}$, Place cell-induced LTP is blocked by adding D-APV ( 50 $\mu \mathrm{m})$ to the bath during replay of cell pair $1_{A, B}$ activity in the presence of carbachol (control path, $129 \pm 24$; test path, $166 \pm 24 ; n=8$ cells $; p>0.05$; cell pair $1_{\mathrm{A}, \mathrm{B}}$ ). Right, Change in EPSC amplitude for each pathway in each experiment. 

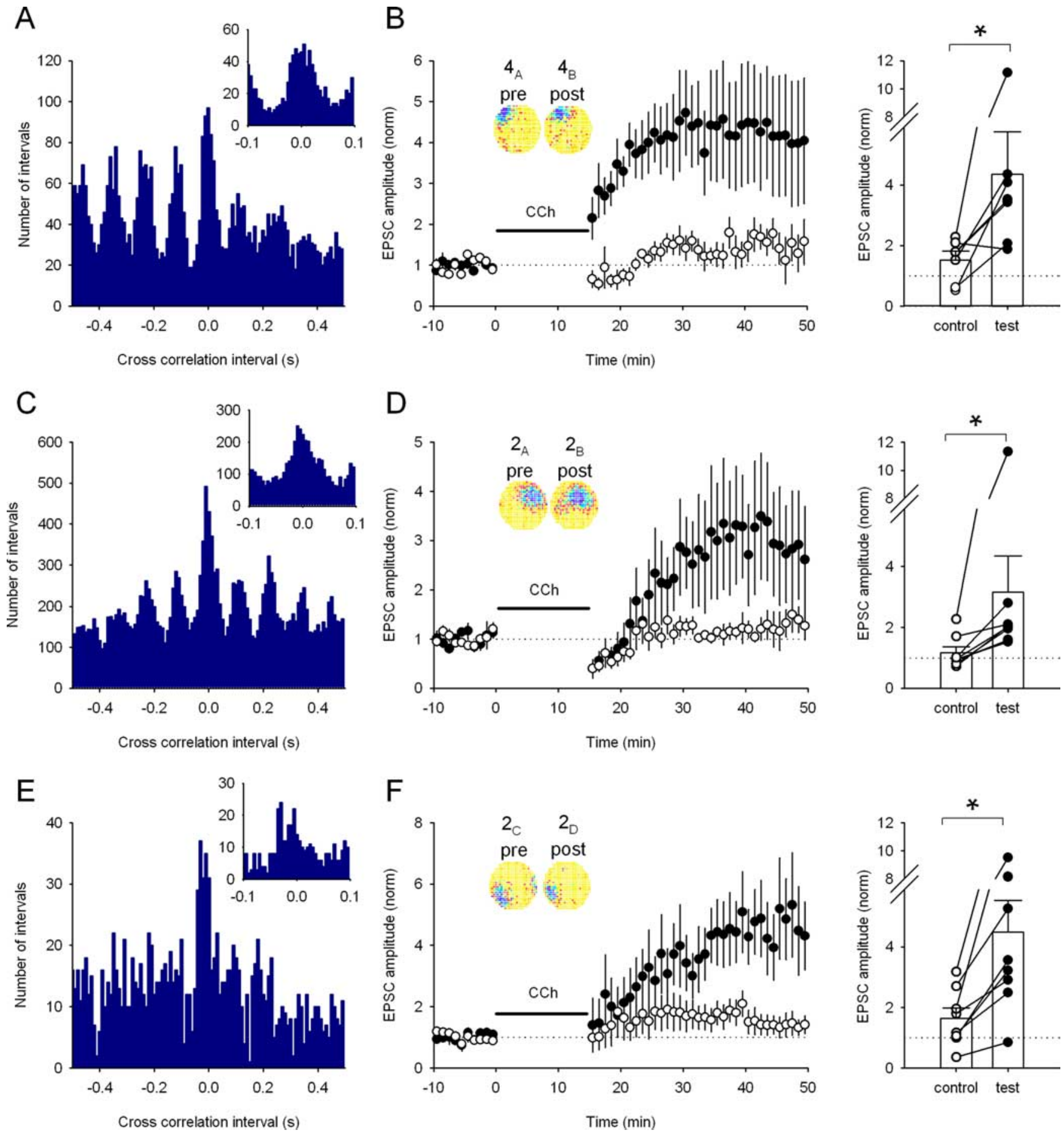

Figure 3. A range of place cell pairs with overlapping firing fields induce LTP $(A)$. Cross-correlation histogram for a pair of CA3 and CA1 place cells $\left(4_{A, B}\right)$ with overlapping fields (10 ms bins). Inset, The same data using $5 \mathrm{~ms}$ bins showing many intervals $<20 \mathrm{~ms}$. $\boldsymbol{B}$, Replay of the cell pair $4_{A, B}$ induces test pathway-specific LTP in a similar manner to overlapping CA1 place cell pairs (control path, $151 \pm 31 \%$; test path, $436 \pm 140 \% ; n=6$ cells; $p<0.05)$. Inset, Firing rate maps showing the similarity of the two firing fields. Right, The change in EPSC amplitude for each pathway in each experiment. ${ }^{*} p<0.05$. C, Cross-correlation histogram for a second place cell pair $\left(2_{A, B}\right)$ with overlapping fields (10 ms bins). Inset, The same data with $5 \mathrm{~ms}$ bins. $D$, Replay of activity from pair $2_{A, B}$ in the presence of carbachol induces pathway-specific LTP (control path, $117 \pm 19 \%$; test path, $317 \pm 117 \% ; n=8$ cells; $p<0.05$ ). Inset, Firing rate maps showing the similarity of the two firing fields. Right, Change in EPSC amplitude for each pathway in each experiment. ${ }^{*} p<0.05$. E, Cross-correlation histogram for a third place cell pair ( $\left.{ }_{c, D}\right)$ with overlapping fields (10 ms bins). Inset, The same data using 5 ms bins. $F$, Replay of activity from pair $2_{C, D}$ also induces pathway-specific LTP in the presence of carbachol (control path, $165 \pm 33 \%$; test path, $449 \pm 105 \% ; n=8$ cells; $p<$ 0.05). Inset, Firing rate maps showing the similarity of the two firing fields. Right, Change in EPSC amplitude for each pathway in each experiment. ${ }^{*} p<0.05$.

(Dan and Poo, 2006). Interestingly, we observed no significant induction of LTD in response to the manipulated place cell pair or, indeed, for any of the unmanipulated pairs. In contrast, we were able to induce robust LTD in these slices using field potential recordings and an artificial induction protocol in which 900 paired pulses at an interstimulus interval of $50 \mathrm{~ms}$ were given at a frequency of $3 \mathrm{~Hz}(72 \pm 8 \% ; n=8 ; p<0.05$; data not shown). These data lead us to the conclusion that, although it is possible to induce LTD in our slices, place cell firing patterns do not to engage these mechanisms. 

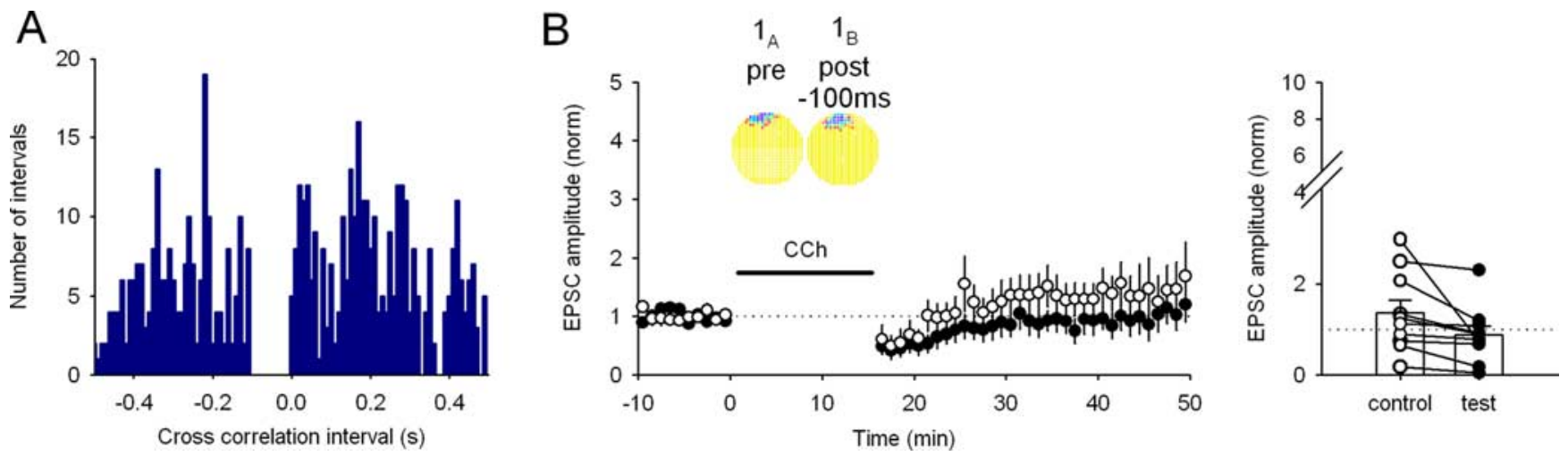

Figure 4. Removal of short interval spike pairs from place cell activity patterns prevents LTP induction. $A$, (ross-correlation histogram (10 ms bins) for cells $1_{A}$ and $1_{B}$ after removal of spikes from cell $1_{B}$ that occurred up to $100 \mathrm{~ms}$ after a spike in cell $1_{A}$. B , Removal of spikes from cell $1_{B}$ prevented the induction of LTP in the presence of carbachol (CCh) (control path, $137 \pm 28 \%$; test path, $88 \pm$ $20 \% ; n=10$ cells; $p>0.05)$. Right, Change in EPSC amplitude for the control and test pathways in each experiment.

\section{Overlapping place cell pairs are required for the induction of synaptic plasticity}

A corollary of the model by which LTP allows synapses between place cells to store spatial information (Muller et al., 1996) is that temporal patterns from place cell pairs with spatially separated firing fields should be unable to induce LTP. To test this, we used a third place cell $\left(1_{\mathrm{C}}\right)$, recorded simultaneously with cells $1_{\mathrm{A}}$ and $1_{\mathrm{B}}$, whose field was far from the others. Cross-correlation analysis confirmed the disjoint firing of cells $1_{\mathrm{A}}$ and $1_{\mathrm{C}}$ (Fig. 5A). Stimulation with pair $1_{\mathrm{A}, \mathrm{C}}$ in the presence of carbachol induced no long-term synaptic plasticity (Fig. $5 B$ ), showing that the nearcoincident activity present in the firing patterns of overlapping place cells is required for LTP. Furthermore, because $1_{A}$ is the same presynaptic cell that caused robust LTP when paired with $1_{\mathrm{B}}$, this experiment also indicates that a particular presynaptic activity pattern alone is insufficient for induction of LTP.

So far, all the cell pairs tested either had highly overlapping or very spatially separated firing fields. We therefore studied two additional place cell pairs, with differing degrees of firing field spatial separation in between these two extremes. One pair had adjacent fields but exhibited very little overlap (cells $2_{\mathrm{E}, \mathrm{D}}$ ). As a consequence, there were very few spike pairs in close temporal proximity (Fig. 5C); induction with this cell pair did not produce LTP despite the presence of carbachol (Fig. 5D). A second place cell pair (cells $3_{\mathrm{A}, \mathrm{B}}$ ) had partially overlapping fields, yielding many spikes in close temporal proximity (Fig. $5 E$ ), and this cell pair induced LTP $(376 \pm 78 \% ; n=7$ cells) (Fig. $5 F)$. If the synaptic connection strength between a place cell pair reflects the proximity of the firing fields (Muller et al., 1996), the amount of LTP induced by the pair should be related to the amount of overlap of the firing fields. However, the precise nature of the strength-separation relationship is not critical as long as strength increases with firing field overlap (Muller et al., 1996). To gain insight into this relationship, we plotted the magnitude of LTP induced by the place cell pairs relative to the degree of overlap of their firing fields. As shown in Figure 5G, synaptic strength increase was steeply dependent on the degree of overlap of the place pair firing fields, and maximal LTP was induced by the place cell fields expressing an overlap index of 0.4 or greater with the cutoff between 0.2 and 0.4 .

LTP induced by place cell firing patterns is rapidly expressed LTP induced by artificial protocols is typically expressed within a few minutes. To determine whether place cell-induced LTP has similar kinetics, we investigated the time course of LTP expres- sion during the induction period. The presence of carbachol during induction delays the appearance of the synaptic strength increase (see Figs. $2 D, E, 3 B, D, F, 5 F$ ) in both test and control pathways. This was revealed by renormalizing the test pathway increase to the control pathway, which showed an abrupt increase in the renormalized test pathway in the majority of experiments immediately after the induction period (data not shown). The presence of carbachol therefore precludes accurate estimation of the time course of LTP expression, and so we sought circumstances that allowed direct monitoring during the induction period. We found that substituting cesium for potassium in the perforated-patch electrode solution enabled expression of place cell LTP, the appearance of which was detectable during the induction period. Consistent with the carbachol experiments, induction with the place cell pair $1_{\mathrm{B}, \mathrm{A}}$ using this recording condition produced robust LTP (Fig. $6 A$ ), whereas induction with the nonoverlapping place cell pair $1_{B, C}$ produced no long-term synaptic plasticity as expected (Fig. 6B). When EPSPs were monitored during the $1_{\mathrm{B}, \mathrm{A}}$ induction period, a progressive amplitude increase was seen (Fig. $6 C$ ), on average from $1.2 \pm 0.5$ to $4.3 \pm 0.9$ $\mathrm{mV}(n=10$ cells) (Fig. $6 D)$. The time course of the increase in EPSP amplitude was well fit by a single exponential with a time constant of 2.74 min (Fig. 6D), demonstrating that the potentiation reached a maximum within a few minutes. Interestingly, the time required for this place cell firing-induced LTP to be fully expressed is similar to the length of time rats typically take to explore a small novel environment (Buzsáki, 2005; Lever et al., 2006) and to the time course over which NMDAR-dependent firing field expansion occurs during running on a closed track (Mehta et al., 2000).

\section{Discussion}

There is a general belief that NMDAR-dependent LTP plays an essential role in hippocampus-based memory (Martin et al., 2000; Nakazawa et al., 2004). Our studies are aimed at understanding a key aspect of this relationship, the specific consequences of connecting place cells with LTP-modifiable synapses. The central observation is that place cell firing patterns from pairs of cells with overlapping fields can induce robust NMDARdependent LTP, whereas activity from pairs of cells with nonoverlapping fields or from single place cells alone does not induce LTP. We also show that the ability to induce LTP requires cholinergic tone indicating that specific behavioral conditions, those associated with increased cholinergic tone in the hippocampus such as exploration and locomotion, are required for the induction of LTP between place cells in vivo. Finally, our data indicate that, 
A

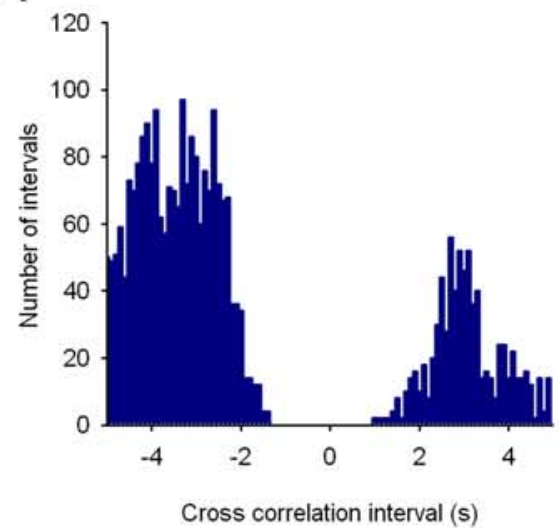

C

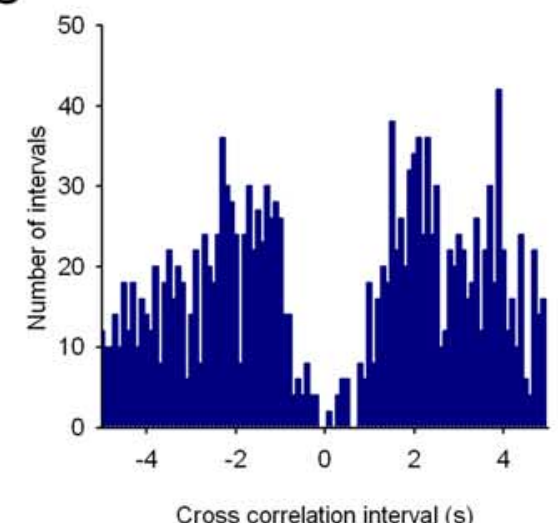

E

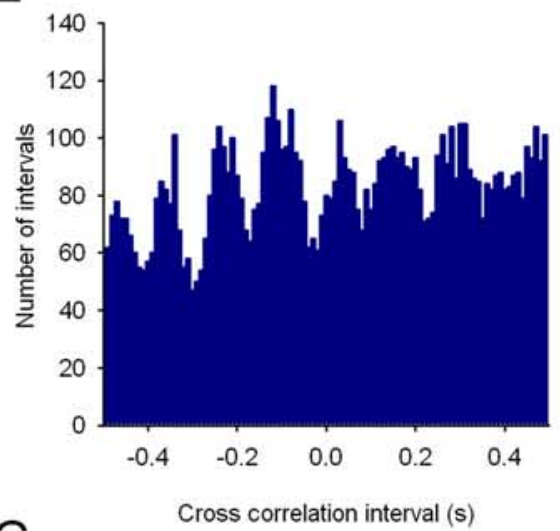

G

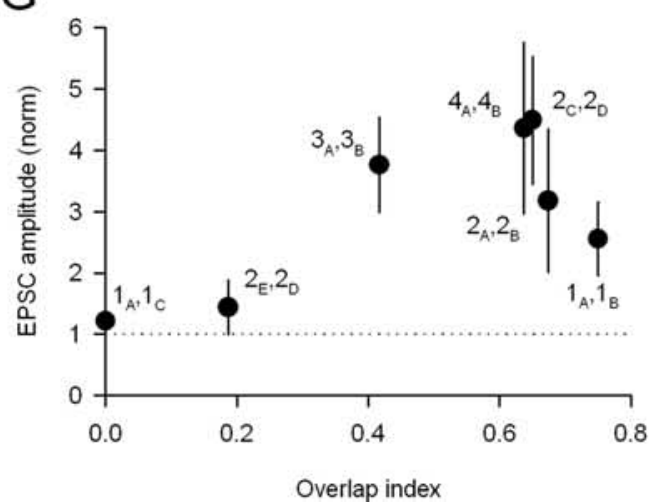

B

D

F
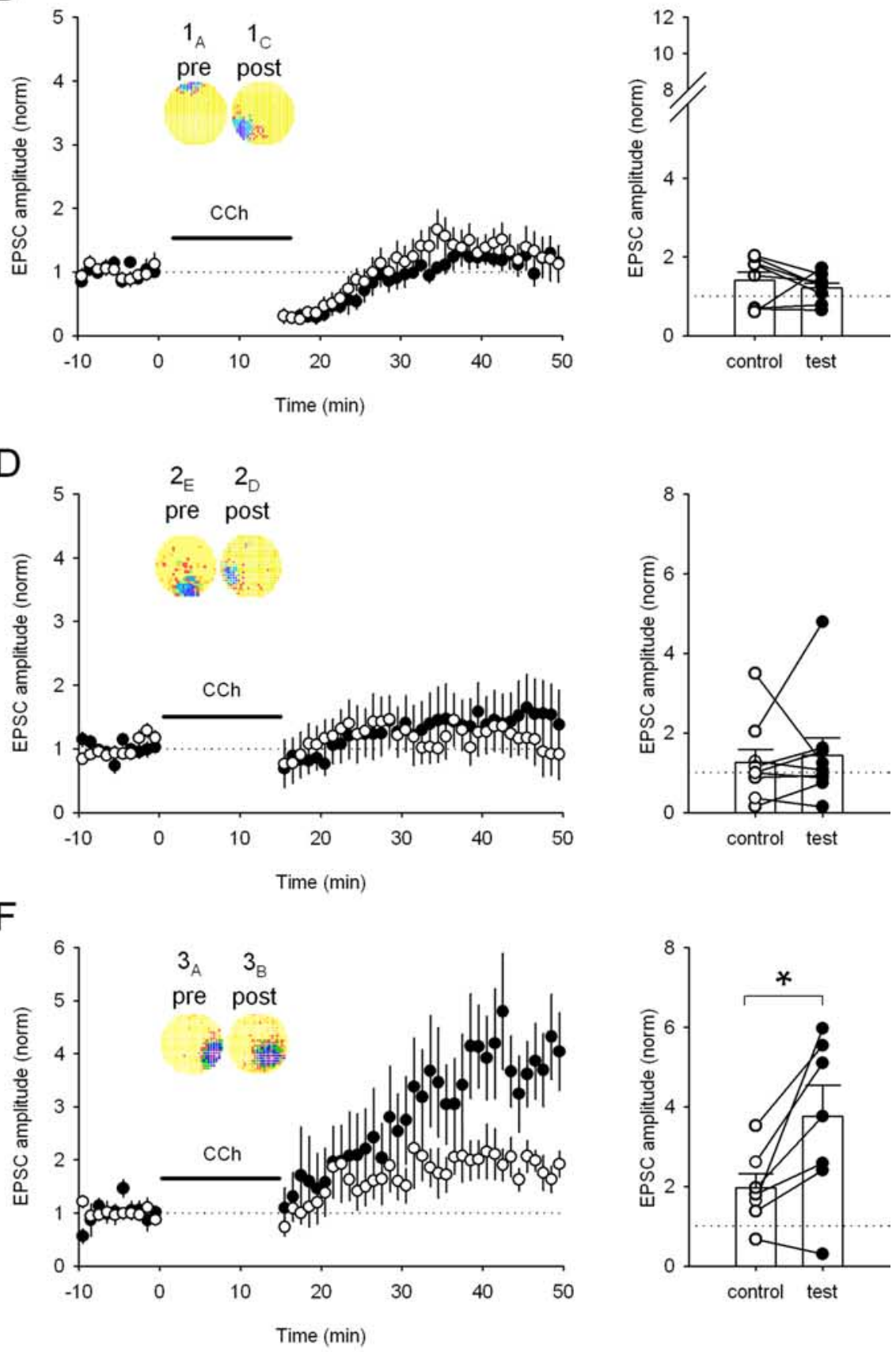

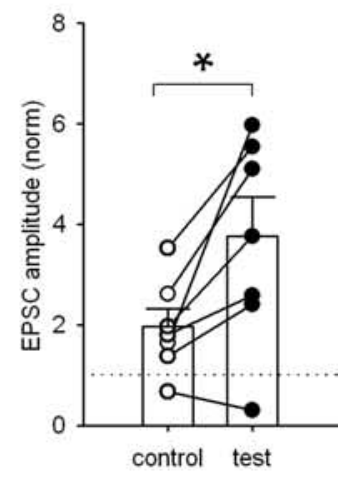

Figure 5. The degree of firing field overlap required for the induction of LTP. $\boldsymbol{A}$, The cross-correlation histogram for the nonoverlapping firing fields of cell pair $1_{\mathrm{A}, \mathrm{C}}$ ( $100 \mathrm{~ms}$ bins). $\boldsymbol{B}$, No long-term synaptic plasticity occurs after stimulation according to the nonoverlapping pair $1_{A, c}$ in the presence of carbachol (CCh) (control path, $140 \pm 22 \%$; test path, $121 \pm 13 \% ; n=8$ cells; $\left.p>0.05\right)$. Inset, The two firing field representations; note the lack of overlap in the firing fields. Right, Change in EPSC amplitude for each pathway in each experiment. $\boldsymbol{C}$, The (Figure legend continues.) 
although there is a requirement for nearcoincident presynaptic and postsynaptic activity, the precise temporal structure of the near-coincident activity is not important for LTP induction. Moreover, LTD is never induced despite the presence of spike intervals that would be expected from STDP models to produce LTD.

\section{Role of the cholinergic system in place} cell firing-induced LTP

An important finding in the present study is that LTP induction by firing patterns from pairs of overlapping place cells requires carbachol. Carbachol mimics the elevated cholinergic tone in the hippocampus during locomotion (Hasselmo, 2006), the behavioral circumstances in which maps are formed from place cell ensembles (Wilson and McNaughton, 1993). The carbachol requirement for LTP is consistent with work showing that carbachol also regulates LTP and LTD induction by artificial stimulus patterns in hippocampal slices (Huerta and Lisman, 1993, 1995) and that LTP magnitude is enhanced in vivo when cholinergic tone in the intact hippocampus is highest (Ovsepian et al., 2004). Our data demonstrate that cholinergic receptors gate LTP induction during combined presynaptic and postsynaptic activity patterns similar to those in vivo. This indicates a requisite role for cholinergic receptor activation during LTP induction in the hippocampus above and beyond the modulatory role reported previously (Ovsepian et al., 2004; Shinoe et al., 2005). It is thought that cholinergic enhancement of LTP involves muscarinic receptors (Ovsepian et al., 2004; Shinoe et al., 2005), leading to either an increase in membrane excitability (Ben-Ari et al., 1981) or the enhancement of NMDARmediated transmission (Markram and Segal, 1990). Our results suggest that an increase in membrane excitability via the suppression of a potassium conductance is the most likely mechanism because adding cesium ions to the intracellular solution
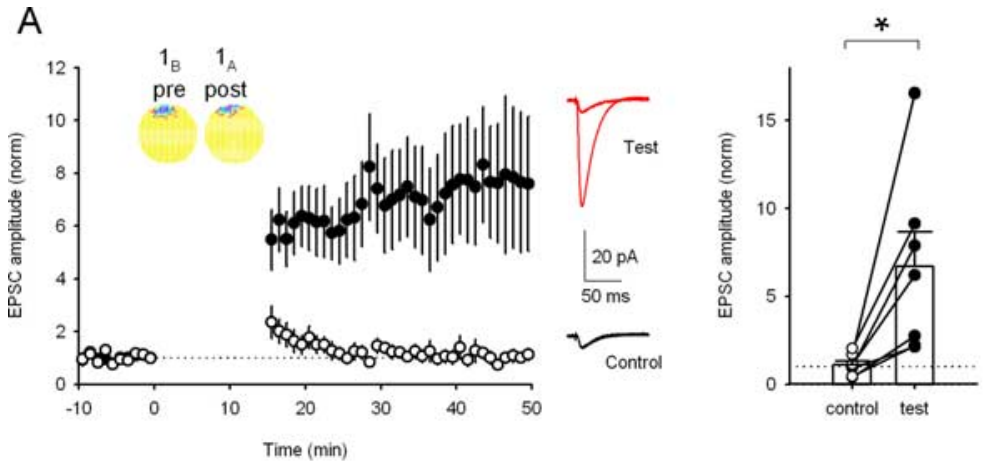

B
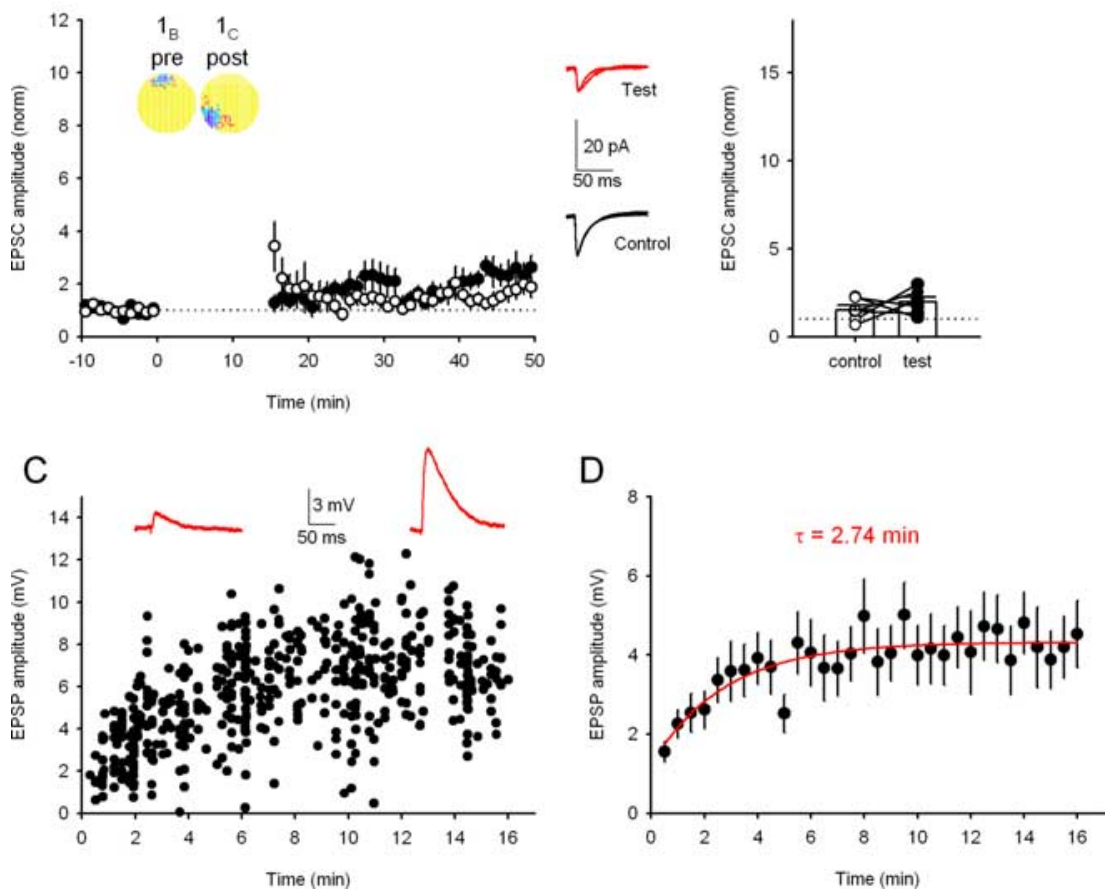

Figure 6. Measuring the time constant of LTP induction during stimulation by activity from place cells with overlapping fields. $A$, Substituting cesium for potassium ions in the recording pipette permits LTP induction by stimulation from overlapping cell pair $1_{B, A}$ in the absence of carbachol (control path, $109 \pm 23 \%$; test path, $669 \pm 196 \%$ test; $n=7$ cells; $p<0.05$ ). Inset, Firing rate maps showing the similarity of the two firing fields. Middle, Averaged traces of EPSCs recorded before and after the replayed activity for test and control pathways from a single experiment. Right, Change in EPSC amplitude for each pathway in each experiment. ${ }^{*} p<0.05$. $\boldsymbol{B}$, Substituting cesium for potassium ions in the recording pipette did not result in pathway specific synaptic LTP for the nonoverlapping firing fields $1_{B, C}$ in the absence of carbachol (control path, $151 \pm 26 \%$; test path, $97 \pm 30 \%$; $n=6$ cells; $p>0.05$ ). Middle, Averaged traces of EPSCs recorded before and after the replayed activity for test and control pathways in a single experiment. Right, Change in EPSC amplitude for each pathway in each experiment. C, Example experiment showing the EPSP amplitudes elicited by each axonal stimulation during the $16 \mathrm{~min}$ LTP induction period for cell pair $1_{B, A}$. Above are example EPSPs taken during the first minute (left) and after $15 \mathrm{~min}$ (right). $\boldsymbol{D}$, Average data from 10 experiments as shown in C. The single-exponential fit (red line) has a time constant of $2.74 \mathrm{~min}$.

\footnotetext{
(Figure legend continued.) cross-correlation histogram for the adjacent firing fields of cell pair $2_{E, D}(100 \mathrm{~ms}$ bins). $\boldsymbol{D}$, No long-term synaptic plasticity occurs after stimulation according to the adjacent pair $2_{E, D}$ in the presence of carbachol (control path, $126 \pm 33 \%$; test path, $144 \pm 44 \%$; $n=9$ cells; $p>0.05$ ). Inset, The two firing field representations; note the adjacent nature of the firing fields. Right, Change in EPSC amplitude for each pathway in each experiment. $\boldsymbol{E}$, Cross-correlation histogram for a place cell pair with partially overlapping fields $\left(3_{A, B}\right)(10 \mathrm{~ms}$ bins). $\boldsymbol{F}$, Replay of activity from pair $3_{A, B}$ in the presence of carbachol induces LTP (control path, $197 \pm 35 \%$; test path, $376 \pm 78 \% ; n=7$ cells; $p<0.05$ ). Inset, Firing rate maps showing the two firing fields. Right, Change in EPSC amplitude for each pathway in each experiment. ${ }^{*} p<$ 0.05. G, Overlap of firing field pairs is required for LTP induction. Each pair used in this study is plotted illustrating the average amount of LTP induced in the test pathway versus the degree of firing field overlap calculated as the overlap index.
}

mimicked the permissive effect of carbachol on LTP. However, we cannot rule out additional direct effects of muscarinic receptor activation on NMDA receptors. In addition, the present experiments do not address whether other neuromodulators can also gate place cell firing-induced LTP (Seol et al., 2007). However, acetylcholine release in the hippocampus is associated with exploration and enhanced spatial learning, indicating that cholinergic modulation of LTP associated with place cell firing is most physiologically relevant for generation of the spatial map.

\section{Properties of place cell firing-induced LTP}

Our observations on the properties of place cell firing-induced LTP conform to many expectations based on artificial LTP in- 
duction protocols (Malenka and Bear, 2004). Place cell firinginduced LTP is NMDAR dependent, requires near-coincident presynaptic and postsynaptic activity, and is input specific. Interestingly, the magnitude of the induced potentiation (approximately threefold to fourfold) is considerably greater than the LTP typically induced by artificial induction protocols (Kauer et al., 1988; Bashir et al., 1993; Zamanillo et al., 1999), suggesting that in vivo place cell firing patterns may optimally drive LTP induction mechanisms.

The overlapping place cell pair firing patterns used to induce LTP exhibit differences in the relative timing of action potentials, between cell pairs and within the cells in the same pair. Despite these spike timing differences, robust LTP of a similar magnitude was induced by the firing patterns of all five overlapping pairs tested. Moreover, presynaptic/postsynaptic switching of a given cell pair, such that the temporal order of spikes is reversed, still yielded robust LTP rather than reversing the sign of plasticity to produce LTD, an outcome contrary to predictions based on popular simple STDP models for synaptic plasticity (Song et al., 2000; Froemke et al., 2006) but in broad agreement with other recent hippocampal studies using artificial induction protocols (Wittenberg and Wang, 2006; Buchanan and Mellor, 2007). However, we note that place cell firing patterns do not appear to induce LTD, although they may contain appropriate presynaptic and postsynaptic spike intervals according to STDP rules. LTD can also be readily induced with artificial protocols; however, our findings suggest that LTD does not play a role in storing distance information for pairs of established place cells.

\section{Place cell LTP and a graph-based hippocampal spatial map}

The empirical finding that LTP is induced by paired place cell firing is an important component for theories of how the hippocampus enables spatial navigation. We emphasize, however, that this finding also supports the idea that a specific item of information, a real-world distance, can be stored in an individual plastic synapse that connects a pair of place cells. A network recurrently connected by such synapses can be shown to contain enough information to find optimal paths in open space, to compute detours, and take shortcuts (Muller et al., 1996). Indeed, such a network is able, in principle, to function as the kind of neural representation envisaged by the cognitive mapping theory (O'Keefe and Nadel, 1978). The present results show how a topological map might be formed in a novel environment if the location-specific discharge of place cells is rapidly initiated, as is believed to be the case (Hill, 1978; Wilson and McNaughton, 1993). An important feature of the graph-based representation is that its ability to compute optimal paths is mostly insensitive to the exact relationship between distance in the environment and synaptic strength as long as strength decreases with distance (Muller et al., 1996). Thus, our findings fully support the graphbased model because place cell pairs with separate nonoverlapping firing fields produce no synaptic modification, whereas pairs with overlapping fields produce LTP whose strength increases very rapidly with the degree of overlap. However, it is important to note that the proposed storage scheme is also fully compatible with the idea that the hippocampal map-like representation is based on attractor dynamics such that discharge by place cells with neighboring fields is mutually, reinforcing but discharge by cells with separated fields is mutually inhibitory (Samsonovich and McNaughton, 1997).

The apparent independence of place cell-induced plasticity from the temporal direction of presynaptic and postsynaptic intervals (as required for STDP) has important implications for the kind of representation that can be supported by place cells connected by LTP-modifiable synapses. If the temporal order of presynaptic and postsynaptic intervals is irrelevant, synapses can encode environmental distance, whereas if strength changes according to STDP-like rules, it instead encodes the path that connects the firing fields of two place cells. In the latter case, the network can represent paths from anywhere to a fixed goal (Blum and Abbott, 1996), but extra properties are required to represent the optimal path from anywhere to anywhere else (Gerstner and Abbott, 1997), as is desirable in a true map-like neural structure. Thus, the missing requirement for precise spike timing for inducing place cell LTP indicates that LTP may encode distance and not path between place cell firing fields so that no additional properties are needed to enable efficient spatial navigation (Muller et al., 1996).

\section{Behavioral consequences}

The behavioral consequences of our findings can be analyzed for two cases. In a familiar environment, CA3-CA1 (and presumably CA3-CA3) synaptic strength can change during exploration, allowing stored information to be rapidly updated if, for example, objects are added to or removed from the environment (Rivard et al., 2004). The spatial map is modifiable in such a way because its constituent plastic synapses are exposed to temporal firing patterns that reflect the local connectivity of space. In a novel environment in which place cell fields are generated very rapidly, synaptic strengths are adjusted during exploration according to the distance between presynaptic and postsynaptic cell firing fields until the strengths reach their steady state. This is consistent with the observation that new place cell activity can be initiated and new spatial memory acquired during blockade of NMDARs, although both are labile, suggesting that such NMDARdependent plasticity is required to stabilize a place cell-based map (Muller et al., 1996; Kentros et al., 1998; Buzsáki, 2005; McDonald et al., 2005; O'Neill et al., 2008). These considerations suggest that NMDAR-based LTP is responsible for permanently establishing synaptic weights in the hippocampus for a stable map.

\section{References}

Bashir ZI, Bortolotto ZA, Davies CH, Berretta N, Irving AJ, Seal AJ, Henley JM, Jane DE, Watkins JC, Collingridge GL (1993) Induction of LTP in the hippocampus needs synaptic activation of glutamate metabotropic receptors. Nature 363:347-350.

Ben-Ari Y, Krnjević K, Reinhardt W, Ropert N (1981) Intracellular observations on the disinhibitory action of acetylcholine in the hippocampus. Neuroscience 6:2475-2484.

Bi GQ, Poo MM (1998) Synaptic modifications in cultured hippocampal neurons: dependence on spike timing, synaptic strength, and postsynaptic cell type. J Neurosci 18:10464-10472.

Bliss TV, Collingridge GL (1993) A synaptic model of memory: long-term potentiation in the hippocampus. Nature 361:31-39.

Blum KI, Abbott LF (1996) A model of spatial map formation in the hippocampus of the rat. Neural Comput 8:85-93.

Buchanan KA, Mellor JR (2007) The development of synaptic plasticity induction rules and the requirement for postsynaptic spikes in rat hippocampal CA1 pyramidal neurones. J Physiol 585:429-445.

Buzsáki G (2002) Theta oscillations in the hippocampus. Neuron 33:325-340.

Buzsáki G (2005) Theta rhythm of navigation: link between path integration and landmark navigation, episodic and semantic memory. Hippocampus 15:827-840.

Chapman CA, Lacaille JC (1999) Cholinergic induction of theta-frequency oscillations in hippocampal inhibitory interneurons and pacing of pyramidal cell firing. J Neurosci 19:8637-8645.

Dan Y, Poo MM (2006) Spike timing-dependent plasticity: from synapse to perception. Physiol Rev 86:1033-1048. 
Dobrunz LE, Stevens CF (1999) Response of hippocampal synapses to natural stimulation patterns. Neuron 22:157-166.

Dudar JD, Whishaw IQ, Szerb JC (1979) Release of acetylcholine from the hippocampus of freely moving rats during sensory stimulation and running. Neuropharmacology 18:673-678.

Dudek SM, Bear MF (1992) Homosynaptic long-term depression in area $\mathrm{CAl}$ of hippocampus and effects of $\mathrm{N}$-methyl-D-aspartate receptor blockade. Proc Natl Acad Sci U S A 89:4363-4367.

Dunwiddie T, Lynch G (1978) Long-term potentiation and depression of synaptic responses in the rat hippocampus: localization and frequency dependency. J Physiol 276:353-367.

Froemke RC, Dan Y (2002) Spike-timing-dependent synaptic modification induced by natural spike trains. Nature 416:433-438.

Froemke RC, Tsay IA, Raad M, Long JD, Dan Y (2006) Contribution of individual spikes in burst-induced long-term synaptic modification. J Neurophysiol 95:1620-1629.

Gerstner W, Abbott LF (1997) Learning navigational maps through potentiation and modulation of hippocampal place cells. J Comput Neurosci 4:79-94.

Hasselmo ME (2006) The role of acetylcholine in learning and memory. Curr Opin Neurobiol 16:710-715.

Hill AJ (1978) First occurrence of hippocampal spatial firing in a new environment. Exp Neurol 62:282-297.

Huerta PT, Lisman JE (1993) Heightened synaptic plasticity of hippocampal Cal neurons during a cholinergically induced rhythmic state. Nature 364:723-725.

Huerta PT, Lisman JE (1995) Bidirectional synaptic plasticity induced by a single burst during cholinergic theta-oscillation in Cal in-vitro. Neuron 15:1053-1063.

Isaac JT, Hjelmstad GO, Nicoll RA, Malenka RC (1996) Long-term potentiation at single fiber inputs to hippocampal CAl pyramidal cells. Proc Natl Acad Sci U S A 93:8710-8715.

Kauer JA, Malenka RC, Nicoll RA (1988) A persistent postsynaptic modification mediates long-term potentiation in the hippocampus. Neuron 1:911-917.

Kentros C, Hargreaves E, Hawkins RD, Kandel ER, Shapiro M, Muller RV (1998) Abolition of long-term stability of new hippocampal place cell maps by NMDA receptor blockade. Science 280:2121-2126.

Larson J, Wong D, Lynch G (1986) Patterned stimulation at the thetafrequency is optimal for the induction of hippocampal long-term potentiation. Brain Res 368:347-350.

Lee I, Rao G, Knierim JJ (2004) A double dissociation between hippocampal subfields: differential time course of CA3 and CA1 place cells for processing changed environments. Neuron 42:803-815.

Leung LS, Shen B, Rajakumar N, Ma J (2003) Cholinergic activity enhances hippocampal long-term potentiation in CA1 during walking in rats. J Neurosci 23:9297-9304.

Lever C, Burton S, O'Keefe J (2006) Rearing on hind legs, environmental novelty, and the hippocampal formation. Rev Neurosci 17:111-133.

Li XG, Somogyi P, Ylinen A, Buzsáki G (1994) The hippocampal CA3 network: an in vivo intracellular labeling study. J Comp Neurol 339:181-208.

Magee JC, Johnston D (1997) A synaptically controlled, associative signal for Hebbian plasticity in hippocampal neurons. Science 275:209-213.

Malenka RC, Bear MF (2004) LTP and LTD: an embarrassment of riches. Neuron 44:5-21.

Malinow R, Tsien RW (1990) Presynaptic enhancement shown by wholecell recordings of long-term potentiation in hippocampal slices. Nature 346:177-180.

Markram H, Segal M (1990) Acetylcholine potentiates responses to $N$-methyl-D-aspartate in the rat hippocampus. Neurosci Lett 113:62-65.
Markram H, Lübke J, Frotscher M, Sakmann B (1997) Regulation of synaptic efficacy by coincidence of postsynaptic APs and EPSPs. Science 275:213-215.

Martin SJ, Grimwood PD, Morris RGM (2000) Synaptic plasticity and memory: an evaluation of the hypothesis. Annu Rev Neurosci 23:649-711.

McDonald RJ, Hong NS, Craig LA, Holahan MR, Louis M, Muller RU (2005) NMDA-receptor blockade by CPP impairs post-training consolidation of a rapidly acquired spatial representation in rat hippocampus. Eur J Neurosci 22:1201-1213.

Mehta MR, Quirk MC, Wilson MA (2000) Experience-dependent asymmetric shape of hippocampal receptive fields. Neuron 25:707-715.

Muller RU, Kubie JL, Ranck JB Jr (1987) Spatial firing patterns of hippocampal complex-spike cells in a fixed environment. J Neurosci 7:1935-1950

Muller RU, Stead M, Pach J (1996) The hippocampus as a cognitive graph. J Gen Physiol 107:663-694.

Nakazawa K, McHugh TJ, Wilson MA, Tonegawa S (2004) NMDA receptors, place cells and hippocampal spatial memory. Nat Rev Neurosci 5:361-372.

O’Keefe J, Dostrovsky J (1971) The hippocampus as a spatial map. Preliminary evidence from unit activity in the freely-moving rat. Brain Res 34:171-175.

O'Keefe J, Nadel L (1978) The Hippocampus as a cognitive map. Oxford: Clarendon.

O’Neill J, Senior TJ, Allen K, Huxter JR, Csicsvari J (2008) Reactivation of experience-dependent cell assembly patterns in the hippocampus. Nat Neurosci 11:209-215.

Ovsepian SV, Anwyl R, Rowan MJ (2004) Endogenous acetylcholine lowers the threshold for long-term potentiation induction in the CA1 area through muscarinic receptor activation: in vivo study. Eur J Neurosci 20:1267-1275.

Rivard B, Li Y, Lenck-Santini PP, Poucet B, Muller RU (2004) Representation of objects in space by two classes of hippocampal pyramidal cells. J Gen Physiol 124:9-25.

Samsonovich A, McNaughton BL (1997) Path integration and cognitive mapping in a continuous attractor neural network model. J Neurosci 17:5900-5920

Seol GH, Ziburkus J, Huang S, Song L, Kim IT, Takamiya K, Huganir RL, Lee HK, Kirkwood A (2007) Neuromodulators control the polarity of spiketiming-dependent synaptic plasticity. Neuron 55:919-929.

Shinoe T, Matsui M, Taketo MM, Manabe T (2005) Modulation of synaptic plasticity by physiological activation of M-1 muscarinic acetylcholine receptors in the mouse hippocampus. J Neurosci 25:11194-11200.

Sjöström PJ, Turrigiano GG, Nelson SB (2001) Rate, timing, and cooperativity jointly determine cortical synaptic plasticity. Neuron 32:1149-1164

Song S, Miller KD, Abbott LF (2000) Competitive Hebbian learning through spike-timing-dependent synaptic plasticity. Nat Neurosci 3:919-926.

Sorra KE, Harris KM (1993) Occurrence and 3-dimensional structure of multiple synapses between individual radiatum axons and their target pyramidal cells in hippocampal area CA1. J Neurosci 13:3736-3748.

Wilson MA, McNaughton BL (1993) Dynamics of the hippocampal ensemble code for space. Science 261:1055-1058.

Wittenberg GM, Wang SSH (2006) Malleability of spike-timing-dependent plasticity at the CA3-CA1 synapse. J Neurosci 26:6610-6617.

Zamanillo D, Sprengel R, Hvalby O, Jensen V, Burnashev N, Rozov A, Kaiser KM, Köster HJ, Borchardt T, Worley P, Lübke J, Frotscher M, Kelly PH, Sommer B, Andersen P, Seeburg PH, Sakmann B (1999) Importance of AMPA receptors for hippocampal synaptic plasticity but not for spatial learning. Science 284:1805-1811. 